\title{
Metodologia para um saber e um fazer geo-histórico: análise de espacialidades pretéritas utilizando instrumentos computacionais
}

\author{
[ Methodology for a geo-historical knowledge and practic: \\ analysis of preterit spatialities using computer tools
}

\section{Eduardo Dutenkefer ${ }^{\mathrm{I}}$}

\begin{abstract}
Metodologia desenvolvida no âmbito do projeto de bolsa de produtividade da professora doutora Iris Kantor (do Departamento de História da Faculdade de Filosofia, Letras e Ciências Humanas - FFLCH da Universidade de São Paulo) no Conselho Nacional de Desenvolvimento Científico e Tecnológico - CNPq: "Mapa para um novo império (I750-I850)".
\end{abstract}

RESUMO - Utilizando instrumentos computacionais, apresentamos neste trabalho uma proposta metodológica para análise de mapas antigos com ênfase em três aspectos: sua geometria, seu georreferenciamento e sua vetorização. Diferentemente de outras metodologias orientadas na precisão cartográfica e em posições absolutas, esta opta por propor um georreferenciamento relativo, isto é, estabelecer relações de feições, lugares e trajetórias que o mapa antigo possa manter com os mapas contemporâneos sem, contudo, distorcer significativamente as feições originais do mapa em estudo. • PALAVRAS-CHAVE · SIG histórico; georreferen- ciamento relativo; geo-história. • ABSTRACT . Using computational tools, we present in this paper a methodology for analysis of old maps with emphasis on three aspects: its geometry, its georeferencing and its vectorization. Unlike other methodologies aimed at mapping accuracy and absolute positions, it chooses to establish a relative georeferencing, this is, establish relationships of features, locations and trajectories that the ancient map could establish with contemporary maps, without, nonetheless, distorting significantly the original features map of study. - KEYWORDS - Historical GIS; relative georeferencing; geohistory.

Recebido em 22 de março de 2016

Aprovado em II de julho de 2016

DUTENKEFER, Eduardo. Metodologia para um saber e um fazer geo-histórico: análise de espacialidades pretéritas utilizando instrumentos computacionais. Revista do Instituto de Estudos Brasileiros, Brasil, n. 65, p. 57-7I, dez. 2016.

DOI: http://dx.doi.org/Io.II606/issn.23I6-90IX.voi65p57-7I

I Universidade de São Paulo (USP, São Paulo, SP, Brasil). 
O mapa pode sugerir uma imagem que representa concretamente um espaço definido pela ciência matemática, bem como um produto de uma representação cultural e social mais ampla, ambos elaborados por "artesãos cartógrafos".

Entre outras definições, o mapa é uma abstração da realidade espacial construída por operadores sociais que a modelam e a codificam com o propósito de que seja apreendida. Além de representar fenômenos espaciais, ele tem o poder visual de espacializar esses fenômenos, sejam eles espaciais ou não, materiais ou ideais.

O mapa como produto de uma representação de nosso passado social oferece, ao olhar geográfico, representações de espacialidades pretéritas que propiciam aos pesquisadores um saber e um fazer geo-histórico, isto é, compor uma explicação de eventos e estabelecer uma cronologia de processos históricos a partir da localização e da análise de fenômenos espaciais que os mapas podem revelar.

Com o uso mais frequente de instrumentos computacionais, como, por exemplo, o Sistema de Informações Geográficas - SIG, em pesquisas geográficas e históricas, apresentamos neste trabalho uma proposta metodológica para esse fazer geo-histórico. Este exercício metodológico tem as suas principais diretrizes e orientações aplicadas na análise da Carta geographica de projecçaõ espherica orthogonal da Nova Lusitania ou America Portugueza e Estado do Brazil, de Antônio Pires da Silva Pontes Leme, I798, utilizando aplicativos computacionais para análise de sua geometria e da execução do seu georreferenciamento e vetorização.

Além de propor uma metodologia específica para esse mapa, ela pode ser aplicada na compreensão das relações dos objetos espaciais presentes em mapas históricos produzidos em diferentes épocas. Como diferencial de outras metodologias orientadas na precisão cartográfica e em seu georreferenciamento baseado em posições absolutas, esta opta por propor um georreferenciamento relativo, isto é, estabelecer relações de feições, lugares, trajetórias que o mapa antigo possa manter com os mapas contemporâneos sem, contudo, distorcer as feições originais do mapa em estudo.

É importante salientar que esta proposta metodológica, baseada em um georreferenciamento relativo, estará atrelada a um nível "absoluto" de precisão atual, pois utilizamos um mapa com técnicas cartográficas contemporâneas como referência para este trabalho, como veremos no desenrolar deste artigo. 


\title{
Do anALÓgico aO Digital
}

O Sistema de Informações Geográficas - SIG (em inglês: Geographic Information System - GIS) é um sistema fundamentalmente baseado em computador, por meio do qual o pesquisador coleta, manuseia e analisa dados georreferenciados, isto é, dados que têm referência espacial - a sua localização - ligados a determinado sistema de referencial espacial cartesiano. Contemporaneamente utiliza a combinação de hardware, software, dados e metodologias para produção e análise de informação geográfica ${ }^{2}$ e, em particular para este trabalho, de informações geo-históricas.

Teremos que atribuir a variável espacial aos mapas históricos utilizando sistemas de coordenadas geográficas em aplicativos (softwares) específicos para SIG.

A primeira etapa que conduzirá o objeto - o mapa histórico - a ser incorporado para análise em SIG é transformá-lo do meio analógico para o digital. Nessa etapa será digitalizado em resoluções adequadas para armazenamento em formato matricial ou raster. Com tal procedimento, teremos o mapa em uma estrutura de representação de dados espaciais em que os seus menores elementos - os pixels (picture elements) ou elementos de imagem - estarão na forma de uma matriz de $n$ linhas por $m$ colunas.

Vale destacar um acervo precioso que podemos explorar utilizando esta proposta metodológica: o acervo da Universidade de São Paulo (USP).

\begin{abstract}
A Biblioteca Digital de Cartografia Histórica da Universidade de São Paulo (www. mapashistoricos.usp.br) disponibiliza mapas digitais em alta resolução impressos entre os séculos XV e XIX pertencentes às coleções da Universidade. Cada mapa é acompanhado de referências biográficas e cartobibliográficas, assim como outras informações técnicas, editoriais e históricas relevantes para a análise dos documentos cartográficos. A Biblioteca Digital foi também concebida para rastrear dados de outros sites similares constituindo uma útil ferramenta de pesquisa e comparação entre as diferentes reproduções disponíveis na $\mathrm{WEB}^{3}$.
\end{abstract}

Parte desse acervo já se encontra digitalizada em altas resoluções, isto é, em quantidades de pixels ou pontos por polegada (ppi - pixels per inch), conhecidos também - termo já consagrado no meio técnico - como pontos por polegada (dpi - dots per inch), adequados para preservar o máximo possível da qualidade original dos mapas históricos.

\section{A GEOMETRIA DE MAPAS “ANTIGOS” E "NOVOS”}

Não é uma tarefa simples georreferenciar mapas históricos em SIG. Temos basicamente dois caminhos: georreferenciamento absoluto e/ou relativo.

2 CHRISTOFOLETTI, Antonio; TEIXEIRA, Amandio Luís de Almeida. Sistemas de Informação Geográfica: dicionário ilustrado. São Paulo: Hucitec, I997.

3 KANTOR, Iris. Notas sobre a construção da Biblioteca Digital de Cartografia Histórica da Universidade de São Paulo. In: SIMPÓSIO BRASILEIRO DE CARTOGRAFIA HISTÓRICA, I., 20II. Anais... Paraty, 20II, p. I. 
Georreferenciar absolutamente é estabelecer adequadamente uma relação das feições do mapa histórico com as suas coordenadas geográficas - latitude e longitude. Essa é a primeira dificuldade. Como estabelecer coordenadas cartesianas em mapas que são de épocas em que não havia essa técnica? E, em momentos em que já existia alguma técnica, como estabelecer relações recíprocas com os nossos sistemas de referência contemporâneos sem que suas formas originais fiquem demasiadamente distorcidas? Estamos preocupados com a precisão matemática das localizações espaciais contemporâneas ou com a "precisão" que a cultura da época propiciou na elaboração do mapa?

Existe uma grande diversidade de formas de representações espaciais em nossa cultura. "Cada sociedade tem ou teve sua própria forma de perceber e de produzir imagens espaciais" (Harley, I99I, p. 5)4. Para Harley, o mapa é uma linguagem visual universal e antiga e como um "saber" das diferentes culturas humanas e não como um mero produto técnico. "Os mapas sempre mostram mais que a soma inalterada de um conjunto de técnicas” (Harley, 2005, p. 6I5 - tradução nossa). Com essa convicção esse autor elabora uma definição ampla do mapa para contemplar as diversas culturas humanas em diferentes épocas: "Representação gráfica que facilita a compreensão espacial de objetos, conceitos, condições, processos e fatos do mundo humano".

[Ainda de acordo com Harley, mapas] "são textos no mesmo sentido que o são outros sistemas de signos não verbais como os quadros, o teatro, o cinema, a música, a televisão... são uma linguagem gráfica que se deve codificar. São uma construção da realidade, imagens carregadas de intenções e consequências que se podem estudar nas sociedades de seu tempo" (Harley, 2005, p. 62 - tradução nossa)7.

Como Besse $^{8}$ reflete em seu trabalho, a precisão, a exatitude de um mapa deve ser repensada. Não queremos aqui saber se o mapa em análise é "verdadeiro" ou "falso", ou seja, exato ou inexato, mas se "é utilizável e exato em função da maneira como se queira fazer uso" . O mapa não é espelho da realidade territorial. Temos

4 HARLEY, John Brian. A nova história da cartografia. O Correio da Unesco (Mapas e cartógrafos). Rio de Janeiro, v. I9, n. 8, ago. I99I.

5 Idem, Textos y contextos en la interpretación de los primeros mapas. In: La nueva naturaleza de los mapas. Ensayos sobre la historia de la cartografía. México: Fondo de Cultura Económica, 2005, p. 59-78.

6 HARLEY, John Brian, op. cit., I99I, p. 5.

7 DUTENKEFER, Eduardo. Representações do espaço geográfico: mapas dasimétricos, anamorfose e modelização gráfica. Dissertação (Mestrado em Geografia). Faculdade de Filosofia, Letras e Ciências Humanas, Universidade de São Paulo, São Paulo, 20Io. Disponível em: <http://www.teses.usp.br/teses/disponiveis/8/8136/tde250220II-II5539>. Acesso em: Io abr. 2016.

8 BESSE, J.-M. Cartographie et pensée visuelle. Réflexions sur la schématisation graphique. In: LABOULAIS, I. (Dir.). Les usages des cartes (XVIIe-XIXe siècle). Pour une approche pragmatique des productions cartographiques. Strasbourg: Presses Universitaires de Strasbourg, 2008, p. I9-32.

9 Ibidem, p. 20 (tradução nossa). 
que pensá-lo como um sistema de informações que é construído sobre uma forma esquemática com base em dados "coletados" e interpretados por operadores que possuem questões e intenções ao elaborá-lo. "Todo mapa propõe uma versão ou uma interpretação da realidade territorial à qual ele se refere, em função das intenções que são implementadas em relação a essa realidade. Em outras palavras, não há uma boa versão no geral, mas apenas no contexto dessa intenção"זo.

O mapa "Nova Lusitânia", que utilizamos neste artigo, se insere no período histórico do século XVIII, no qual os esforços do império português estavam voltados para estabelecer posicionamentos mais precisos de seu território em terras brasileiras. $\mathrm{O}$ trabalho de Menezes ${ }^{\text {II }}$, por exemplo, mostra como foi a organização desse esforço português e seus resultados. Particularmente com relação à "carta da Nova Lusitânia", ressalta a ordem do então ministro da Marinha portuguesa "para que fosse elaborada uma Carta Geral do Brasil, utilizando-se para isso das melhores informações que haviam sido utilizadas nas demarcatórias, principalmente aquelas que estivessem representadas por 'seus verdadeiros pontos de latitude e longitude" ${ }^{\text {"ז2 }}$. Cintra ${ }^{\mathrm{I}}$ também trabalha com o chamado "Mapa das Cortes" dessa mesma época, demonstrando as "intenções" I4 do império português com cálculos matemáticos e o quanto eram precisos e/ou imprecisos ${ }^{15}$ em relação às técnicas da época e à nossa atual.

Nesta proposta metodológica estamos focados em compreender as relações dos objetos espaciais presentes nos mapas históricos produzidos em diferentes épocas. Com tal objetivo, optamos por propor um georreferenciamento relativo, isto é, estabelecer relações de feições, lugares, trajetórias que o mapa antigo possa

Io Ibidem, p. 2I (tradução nossa).

II "Os primórdios da cartografia do Império do Brasil remontam ao século XVIII, quando se inicia a missão cartográfica oficial dos padres Diogo Soares e Domingos Capacci, jesuítas, designados em alvará especial por D. João V, Rei de Portugal, para desenvolverem demarcações e posicionamento terrestre preciso.” MENEZES, Paulo Leal de. A cartografia do Império do Brasil. In: SIMPÓSIO LUSO-BRASILEIRO DE CARTOGRAFIA HISTÓRICA, 4. Anais... Porto: Universidade do Porto. p. 3. Disponível em: <http://eventos.letras.up.pt/ivslbch/ comunicacoes/90.pdf >. Acesso em: 20 jun. 2016.

I2 Ibidem, p.5.

I3 CINTRA, Jorge Pimentel. O Mapa das Cortes: perspectivas cartográficas. Anais do Museu Paulista, São Paulo, N. Sér. v. I7, n. 2, jul.- dez. 2009, p. 63-77.

I4 "Após uma análise morfológica qualitativa, passa-se a um exame quantitativo, comparando esse mapa com um atual, bastante preciso: com o auxílio de um programa de cartografia digital e uma planilha eletrônica foram comparadas as coordenadas geográficas (latitude e longitude) de mais de 430 pontos. A quantificação sistemática e detalhada dos erros em diferentes regiões, da costa atlântica à região amazônica, mostrou aspectos surpreendentes de como o Mapa das Cortes (MC) foi habilmente construído. Essa análise permitiu quantificar de maneira mais precisa as distorções, identificando em que locais foram introduzidas e seu caráter indubitavelmente proposital." Ibidem, p. 63.

I5 "A precisão das coordenadas $\left(0,22^{\circ}\right.$ e 0,37\%), indicando que os portugueses possuíam conhecimentos e técnicas para medir coordenadas e desenhar mapas com essa precisão, que não justifica erros da ordem de $3^{\circ}$." Ibidem, p. 70. 
manter com os mapas contemporâneos sem, contudo, distorcer as feições originais do mapa em estudo, e sem "ferir" em demasia as "intenções" e "interpretações" que seu autor, em sua época, "esquematizou” como "realidade territorial”. Queremos primeiramente verificar a geometria dos mapas antigos, e para isso optamos por utilizar o aplicativo MapAnalyst ${ }^{\mathrm{I6}}$ desenvolvido em Java ${ }^{17}$ e mantido por Bernhard Jenny, da Oregon State University, com contribuições de Adrian Weber, do Eidgenössische Technische Hochschule Zürich - ETH Zürich (Instituto Federal de Tecnologia de Zurique). É um aplicativo que roda em todas as principais plataformas de computadores com sistemas operacionais Windows, OS da Apple e Linux. Permite a identificação e a gestão eficiente de pontos de controle de um mapa histórico e a transferência desses dados para um mapa de referência correspondente, calculando grades de distorção, vetores de erro e isolinhas de escala e rotação. Também calcula aproximadamente a escala do mapa histórico, o ângulo de rotação e indicadores estatísticos, e oferece ferramentas interativas para explorar as variações locais de deslocamentos, escala e rotação. Permite, também, que historiadores sem formação técnica especializada analisem a geometria de mapas antigos ${ }^{\mathrm{I}}$.

Esse aplicativo oferece um ponto inicial em nossa metodologia e pode estabelecer relações espaciais do presente com o passado e vice-versa. Estabelece, ainda, as localizações das feições geográficas do mapa antigo e sua relação com um mapa atual sem alterar a geometria do mapa antigo em análise.

Como ensaio, realizamos os primeiros estudos do mapa "Nova Lusitânia” o objetivo de transformá-lo de uma estrutura de dados matricial (raster) para dados em estrutura vetorial, isto é, transformá-los em elementos gráficos geométricos do tipo ponto, linha e polígono.

I6 MapAnalyst - The map historian's tool for the analisys of old maps. Disponível em: <http://mapanalyst. org/>. Acesso em: 8 jan. 2012.

I7 Java é uma linguagem de programação orientada a objeto desenvolvida na década de I990 por uma equipe de programadores chefiada por James Gosling, na empresa SUN (Stanford University Network - Rede da Universidade de Stanford) Microsystems - atualmente é uma subsidiária da Oracle Corporation. CORNELIUS, Barry. Computing services. Java 5 catches up with C\#. University of Oxford, 2004. Disponível em: 〈http://www. barrycornelius.com/papers/java5/onefile/\#body.I_divi.2>. Acesso em: 20 jun. 2016.

I8 JENNY, Bernhard; WEBER, Adrian; HUERNI, Lorenz. Visualizing the planimetric accuracy of historical maps with MapAnalyst. Cartographica: the International Journal for Geographic Information and Geovisualization, v. 42, issue I, 2007, p. 89-94.

I9 LEME, Antônio Pires da Silva Pontes. Carta geographica de projecção espherica orthogonal da Nova Lusitania ou America Portugueza e Estado do Brazil, de I798. Dimensões: 202 cm (larg.) x I99 cm (alt.). Gabinete de Estudos Arqueológicos da Engenharia Militar, Direcção de Infraestruturas do Exército de Portugal. Sobre o mapa "Nova Lusitânia”, ver: KANTOR, Iris. Mapas em trânsito: projeções cartográficas e processo de emancipação política do Brasil (I779-I822). Sevilla, Araucaria, XII, 24, p. IIo-I23, 20Io. Disponível em: <http://www. researchgate.net/publication/4773445I_Mapas_em_trnsito_projees_cartogrficas_e_processo_de_emancipao_ poltica_do_Brasil_(I779-I822) >. Acesso em: I5 fev. 20I4; BUENO, Beatriz P. S.; KANTOR, Iris. Decupando as redes na Carta Geográfica Nova Lusitânia c. I797. Comunicação apresentada no Colóquio de História Colonial, em Belém, Brasil, setembro de 2012. 
No MapAnalist comparamos um mapa atual "oficial", no caso um mapa do Instituto Brasileiro de Geografia - IBGE ${ }^{20}$, em raster com o raster do "Nova Lusitânia". Partimos de I8 pontos (vilas, freguesias) no mapa "Nova Lusitânia" e homólogos do mapa do IBGE. A figura I mostra a tela do MapAnalist com ambos os mapas para comparação.



Figura I - Tela do MapAnalist com os I8 pontos escolhidos no mapa "Nova Lusitânia" (à esquerda) e homólogos no mapa do IBGE e a tela dos pontos selecionados (à direita)

É importante ressaltar que georreferenciamos o mapa do IBGE em aplicativo SIG $\left(\mathrm{ArcGis}^{2 \mathrm{I}}\right.$ ) na projeção original policônica, com meridiano de referência $54^{\circ} \mathrm{W}$. Gr. e paralelo o na escala de I:5.000.000 antes de compararmos no MapAnalist com o "Nova Lusitânia".

A figura 2 mostra a tela principal do MapAnalist com a malha (grids) de distorção. A figura 3, em detalhe, mostra o grid e os vetores de deslocamento (na cor verde) na tela do "Nova Lusitânia" (esquerda). Essas linhas são vetores de deslocamentos (representados como um segmento de reta orientado e com comprimentos calculados pelo aplicativo), demonstrando o quanto os pontos escolhidos no "Nova Lusitânia" estão deslocados em relação a os seus homólogos no mapa do IBGE (direita). A malha de distorção, os pontos e vetores de deslocamentos foram salvos em formato shapefile - formato desenvolvido pela ESRI -, isto é, em formato vetorial como pontos e linhas.

20 República Federativa do Brasil. Mapa político do Brasil. Ministério do Planejamento, Orçamento e Gestão, Instituto Brasileiro de Geografia e Estatística. Diretoria de Geociências. Disponível em: <ftp://geoftp.ibge. gov.br/cartas_e_mapas/mapas_do_brasil/politico/brasil_politico500ok_2004.pdf $\rangle$. Acesso em: 9 jul. 2016. 2I Da empresa Environmental Systems Research Institute - ESRI. 


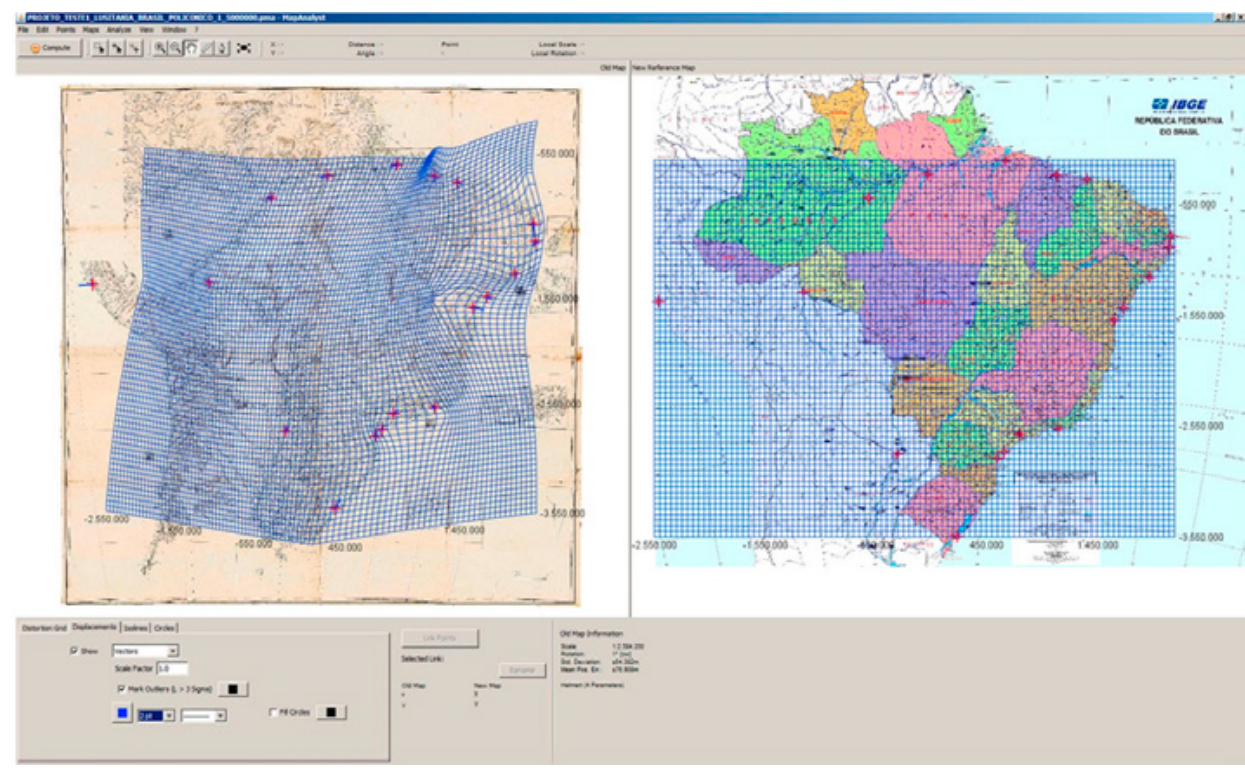

Figura 2 - Tela do MapAnalist evidenciando o grid de distorção e os pontos selecionados

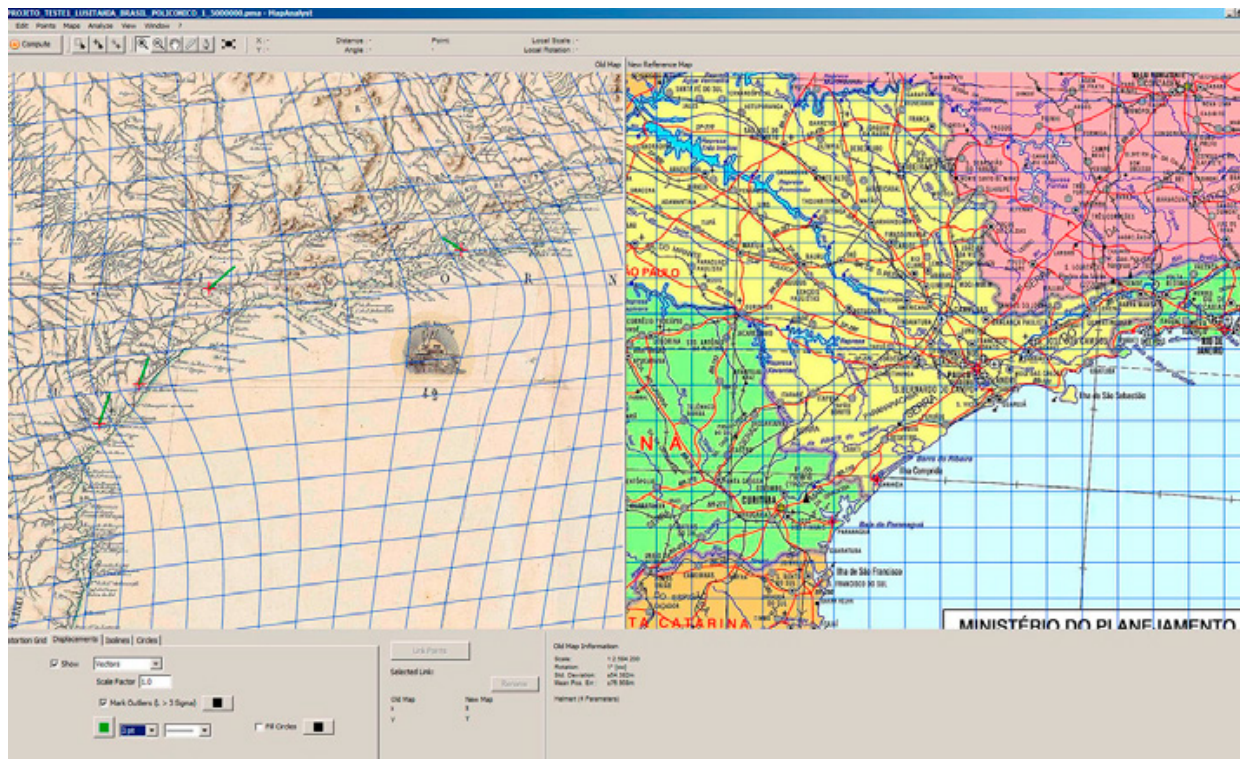

Figura 3 - Detalhe dos mapas na tela do MapAnalist evidenciando o grid de distorção e os vetores de deslocamento

\section{O GEORREFERENCIAMENTO do “NOVA LUSITÂNIA"}

Concluída a etapa anterior, temos agora elementos para georreferenciar em aplicativo SIG o nosso mapa histórico. 
Usamos o software de SIG ArcGis ${ }^{22}$ para prosseguir em nossos procedimentos. Temos como referência o mapa do IBGE em formato raster - já georreferenciado - e trazemos ao ArcGis o mapa "Nova Lusitânia", também em formato raster.

O georreferenciamento do Lusitânia será processado tendo como base os pontos e vetores de deslocamentos originários do MapAnalist (figura 4). Identificamos primeiro o ponto homólogo no mapa histórico - "Nova Lusitânia" -, tendo como referência os pontos do novo mapa - o do IBGE -, que foi importado em formato ponto originário do MapAnalist. Em seguida georreferenciamos o ponto identificado até a "ponta" do vetor de deslocamento (essa "ponta" é o ponto homólogo no mapa histórico "Nova Lusitânia”). O "novo" posicionamento geométrico do "Nova Lusitânia” não sofrerá distorções apreciáveis de sua forma original.

Concluída essa etapa podemos começar a vetorização do mapa histórico.

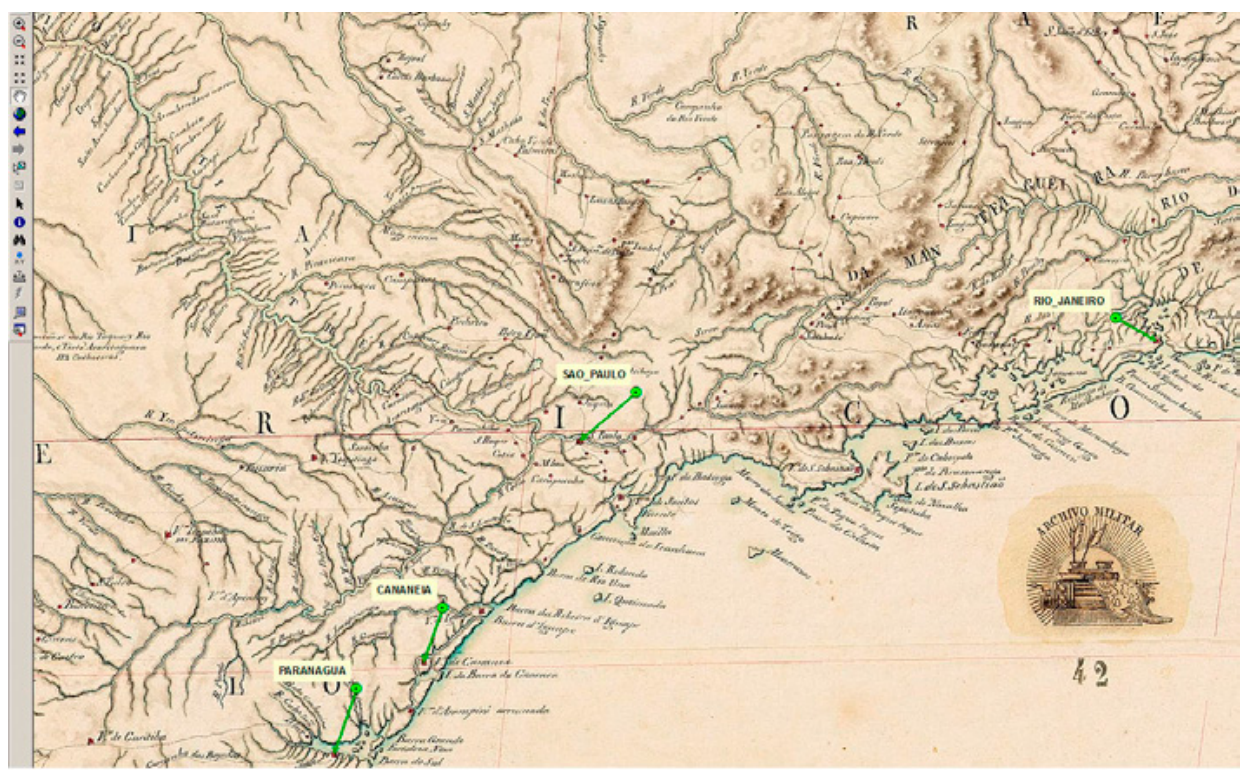

Figura 4- Detalhe do mapa "Nova Lusitânia” georreferenciado. Observamos os vetores de deslocamento já posicionados e os pontos escolhidos como referências no mapa do IBGE. Aplicativo ArcGis

\section{A VETORIZAÇÃo do MAPA HiStórico}

Na figura 5 temos uma ideia da quantidade de objetos geográficos a se transformar de estrutura de dados raster para estrutura vetorial.

22 Podemos também utilizar qualquer outro aplicativo de SIG não comercial, por exemplo, o GvSig (disponível em: 〈http://www.gvsig.org/web〉) ou o Quantum Gis (disponível em: 〈http://www.qgis.org/es/site>). 


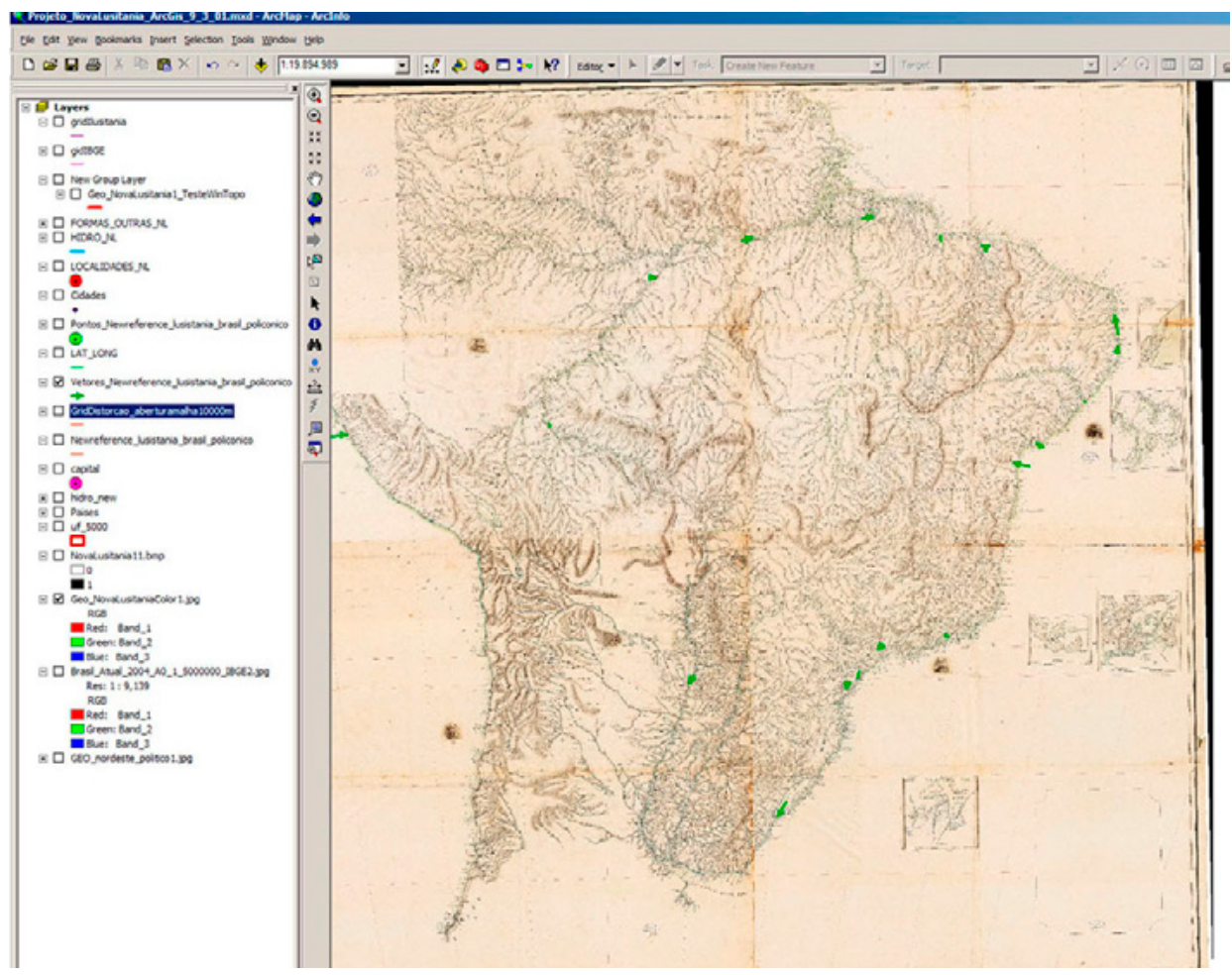

Figura 5 - Imagem em aplicativo SIG da estrutura raster que deverá ser transformada em vetorial

\section{UM APLICATIVO “CORINGA”}

Para facilitar o procedimento de vetorização, optamos pelo aplicativo WinTopo ${ }^{23}$ Freeware (figura 6), que oferece uma boa solução para transformar dados estruturados em raster em dados estruturados em vetor, em particular no formato shapefile para compatibilizar com a maioria dos aplicativos de SIG.

$\mathrm{O}$ aplicativo teve um bom desempenho no processamento da imagem raster do mapa "Nova Lusitânia”. Transformou automaticamente em formato vetorial do tipo linha a maioria das feições encontradas no mapa original (figura 7).

23 WinTopo Raster to Vector Converter. Disponível em: 〈http://www.wintopo.com>. Acesso em: 3 maio 20 II. 


\section{WinTopo Raster to Vector Converter}

Rester to Vector imaging software

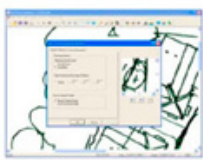

WinTopo is a high qualty sofware appication for comerting TIF, JPG, PNG, GF, BMP hles and scanned mages into usofut veclot fies sutatie for CAD, GIS and CNC apoications WnTepo comes in tro floveurs
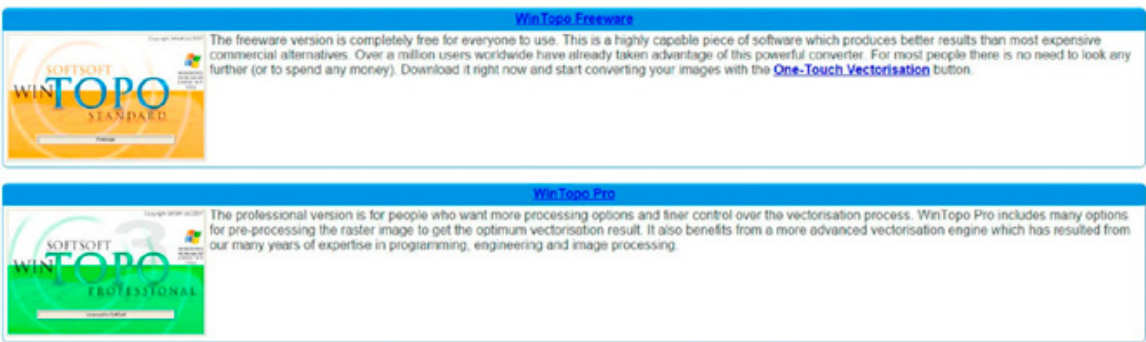

Figura 6 - Tela do site WinTopo

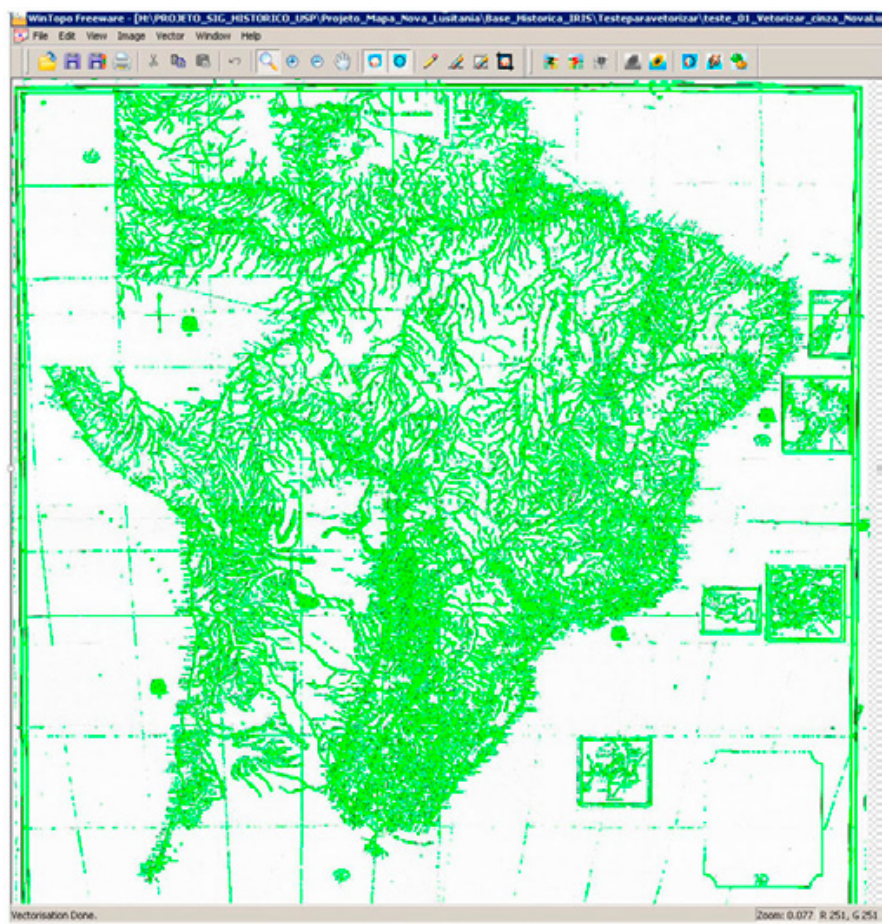

Figura 7-Tela do aplicativo WinTopo com a vetorização automática realizada sobre a imagem raster do mapa "Nova Lusitânia"

Com esse procedimento ganhamos um tempo precioso na transformação do mapa 
original em raster para vetorial. Ele foi acrescentado como mais uma camada em nosso projeto de SIG em ArcGis.

Cabe, contudo, refinar e ajustar essa vetorização para agregarmos informações a esses objetos geográficos e nomeá-los em suas diversas toponímias encontradas no mapa original. Essa é uma vantagem preciosa do SIG: agregar um "banco de dados" com as principais informações extraídas na leitura e interpretação do mapa histórico em estudo.

\section{O MAPA HISTÓRICO EM CAMADAS}

Com as etapas anteriores realizadas, temos agora objetos geográficos do mapa histórico que foram "coletados" e estão representados em formato compatível para serem manuseados, destrinchados, desconstruídos, analisados em camadas separadas ou como um todo.

A possibilidade de trabalhar o mapa histórico em camadas, em planos de informações que o aplicativo de SIG oferece ao pesquisador, abre novos horizontes de interpretações e análises do mapa histórico original.

O mapa em camadas pode revelar novas perspectivas de interpretações que o mapa original não permitia por não ser visualizado com clareza.

Em uma primeira subetapa da vetorização do mapa "Nova Lusitânia", dividimos as camadas em três tipos básicos:

I. camada dos objetos geográficos que dizem respeito ao traçado dos rios em formato de linhas;

2. camada de pontos que dizem respeito a localizações de vilas, freguesias, povoados etc.;

3. por último, camada de áreas que dizem respeito a feições mais próximas a objetos geográficos da forma zonal.

Encontramos pelo caminho outros objetos que não se encaixam em nossa classificação básica. Em particular, acrescentamos uma quarta camada em formato linear para extrair os diversos caminhos de circulação, de "redes" de acessibilidade pertinente ao século que o mapa retrata; e uma quinta representando as "barreiras", inibidores desses percursos sobre o território. Na figura 8 é mostrado um recorte do mapa "Nova Lusitânia" com exemplos dessas representações. 


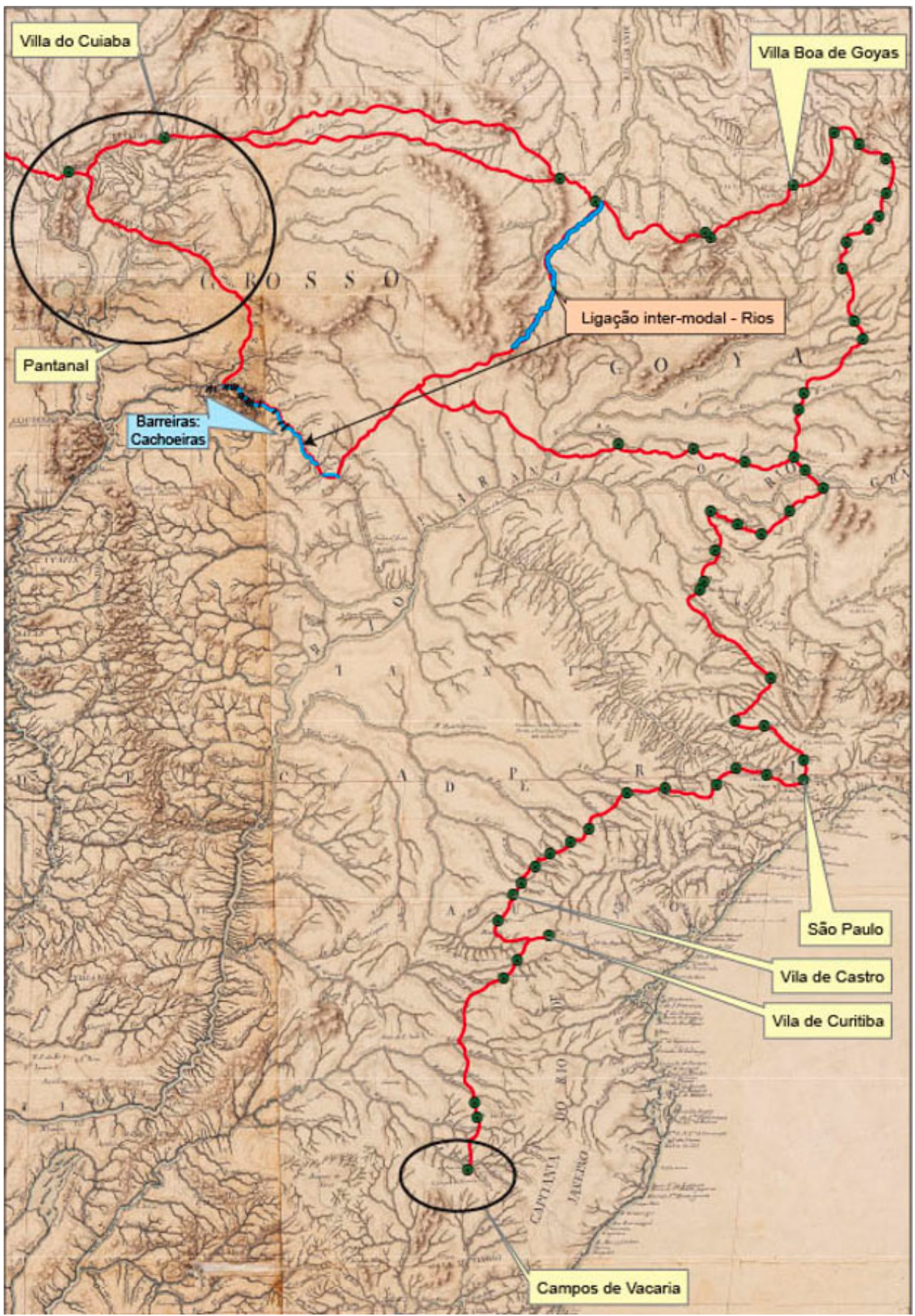

Figura 8 - Caminhos e tipos de ligações entre Paraná, São Paulo e Mato Grosso. Mapa "Nova Lusitânia” 
Metodologicamente, parece-nos ser a última etapa desse percurso. Mas a aventura em percorrer e descobrir novos lugares, caminhos, relações espaciais está apenas no começo.

É o início de uma fase demorada e delicada. Exige disciplina, rigor e fascínio para transformar o mapa histórico em um documento revelador das estruturas espaciais da época em que foi concebido. Espacialidades pretéritas serão reveladas, apreendidas e analisadas. Um "estudo geográfico de processos históricos”24, isto é, um saber e um fazer geo-histórico, estará em desenvolvimento.

\section{SOBRE O AUTOR}

EDUARDO DUTENKEFER é mestre em Geografia e doutorando em Geografia Humana na Faculdade de Filosofia, Letras e Ciências Humanas da Universidade de São Paulo (FFLCH/USP).

E-mail: dutenkefer@gmail.com

\section{REFERÊNCIAS BIBLIOGRÁFICAS}

BESSE, Jean-Marc. Cartographie et pensée visuelle. Réflexions sur la schématisation graphique. In: LABOULAIS, I. (Dir.). Les usages des cartes (XVIIe-XIXe siècle). Pour une approche pragmatique des productions cartographiques. Strasbourg: Presses Universitaires de Strasbourg, 2008, p. I9-32.

BUENO, Beatriz P. S.; KANTOR, Iris. Decupando as redes na Carta Geográfica Nova Lusitânia c.I797. Comunicação apresentada no Colóquio de História Colonial, em Belém, Brasil, setembro de 2012.

CHRISTOFOLETTI, Antonio; TEIXEIRA, Amandio Luís de Almeida. Sistemas de Informação Geográfica: dicionário ilustrado. São Paulo: Hucitec, I997.

CINTRA, Jorge Pimentel. O Mapa das Cortes: perspectivas cartográficas. Anais do Museu Paulista, São Paulo, N. Sér. v.I7, n. 2, jul.-dez. 2009, p. 63-77.

CORNELIUS, Barry. Computing services. Java 5 catches up with C\#. University of Oxford, 2004. Disponível em: 〈http://www.barrycornelius.com/papers/java5/onefile/\#body.__divI.2〉. Acesso em: 20 jun. $20 I 6$.

DUTENKEFER, Eduardo. Representações do espaço geográfico: mapas dasimétricos, anamorfose e modelização gráfica. Dissertação (Mestrado em Geografia). Faculdade de Filosofia, Letras e Ciências Humanas, Universidade de São Paulo, São Paulo, 20Io. Disponível em: <http://www.teses.usp.br/ teses/disponiveis/8/8I36/tde-250220II-II5539>. Acesso: 20 abr. 2016.

GRATALOUP, Christian. Géohistorie. In: LÉVY, Jacques; LUSSAULT, Michel (Org.). Dictionnaire de la géographie et de l'espace des sociétés. Paris: Belin, 2003, p. $40 \mathrm{I}$.

24 GRATALOUP, Christian. Géohistorie. In: LÉVY, Jacques; LUSSAULT, Michel (Org.). Dictionnaire de la géographie et de l'espace des sociétés. Paris: Belin, 2003, p. 401 (tradução nossa). 
HARLEY, John Brian. A nova história da cartografia. O Correio da Unesco (Mapas e cartógrafos), Brasil, ano I9, n. 8, ago. I99I, p. 4-9.

. Textos y contextos en la interpretación de los primeros mapas. In: . La nueva naturaleza de los mapas. Ensayos sobre la historia de la cartografía. México: Fondo de Cultura Económica, 2005, p. 59-78. JENNY, Bernhard; WEBER, Adrian; HUERNI, Lorenz. Visualizing the planimetric accuracy of historical maps with MapAnalyst. Cartographica: the International Journal for Geographic Information and Geovisualization, v. 42, issue I, 2007, p. 89-94.

KANTOR, Iris. Mapas em trânsito: projeções cartográficas e processo de emancipação política do Brasil (I779-I822). Araucaria - Revista iberoamericana de filosofía, política y humanidades, Sevilla, año I2, n. 24, p. IIO-I23, 20Io. Disponível em: 〈http://www.researchgate.net/publication/4773445I_Mapas_em_trnsito_projees_cartogrficas_e_processo_de_emancipao_poltica_do_Brasil_(I779-I822)>. Acesso em: I5 fev. 20I4.

. Notas sobre a construção da Biblioteca Digital de Cartografia Histórica da Universidade de São Paulo. In: SIMPÓSIO BRASILEIRO DE CARTOGRAFIA HISTÓRICA, I., 2OII. Anais... Paraty, $20 I I$.

LEME, Antônio Pires da Silva Pontes. Carta geographica de projecção espherica orthogonal da Nova Lusitania ou America Portugueza e Estado do Brazil, de [I798]. Dimensões: 202 cm (larg.) x I99 cm (alt.). Gabinete de Estudos Arqueológicos da Engenharia Militar, Direcção de Infraestruturas do Exército de Portugal. MENEZES, Paulo Leal de. A cartografia do Império do Brasil. In: SIMPÓSIO LUSO-BRASILEIRO DE CARTOGRAFIA HISTÓRICA, 4. Anais... Porto: Universidade do Porto. p. 3. Disponível em: <http://eventos. letras.up.pt/ivslbch/comunicacoes/90.pdf $>$. Acesso em: 20 jun. 2016. 